ume, he will be interested in 'Principles of Animal Nutrition,' by H. P. Armsby, director of the Pennsylvania State Agricultural Experiment Station, which discusses this and related topics and summarizes a large amount of interesting information. The question is also taken up by Dr. Armsby in 'The Isodynamic Replacement of Nutrients,' ScIEnce, N. S., 18 (1903), No. 459, pp. 481-487.

Some experiments which have to do with temperature during fever with especial relation to the influence of the abnormal body condition on metabolism are summarized in Bulletin No. 45 of the Office of Experiment Stations, entitled 'A Digest of Metabolism Experiments.'

The Jahresbericht der Tier-Chemie contains numerous titles and abstracts of articles which deal with the question under consideration. The Department of Agriculture library contains a set of this journal, which can undoubtedly be found also in a number of other public or university libraries.

C. F. Langworthy.

Office of Experiment Stations, Department of Agriculture.

\section{MATHEMATICS AND METAPHYSICS.}

ON reading the interesting lecture of Professor Josiah Royce on 'The Sciences of the Ideal,' and learning that all leveling and serial relations come from the same root, one is reminded of the computer of the coast survey, who decided that $8 \times 8$ is not exactly 64 , but plus or minus a small quantity, according to the table of logarithms he used. If mathematics and metaphysics coalesce where shall we rest? Will our mathematicians become 'flabbier and flabbier'?

A. Hall.

October 10, 1904.

\section{SPECIAL ARTICLES.}

WHAT IS AN ELECTRIC CURRENT?*

'THE question of the day which seems to appeal most strongly to the physicist is: What is taking place in a metallic conductor on the terminals of some electrical source?

* Abstract from an address on 'Present Problems in Physics,' at the Congress of Arts and Science.
Rowland's rotating disk showed that a positively charged body moving in a positive direction, and a negatively charged body moving in an opposite direction, produce the same electromagnetic effects in the surrounding field.

Rutherford's work in deflecting the electrons of a radioactive body is in entire harmony with Rowland's result. Positively charged masses of radiant matter are deflected in the opposite direction from negatively charged matter, when acted upon by a magnetic field, the masses are, of course, moving in the same direction. These charged particles of moving matter are, in effect, superposed, or perhaps juxtaposed electric currents moving in the same direction. If either the $a$ or the $\beta$ particles could be reversed in direction, then the magnetic field would deflect them in the same direction. They would then each create the same external magnetic effects. They would then represent superposed currents of opposite sign, moving or flowing in opposite directions.

All of this means that a positive current of electricity flowing in a positive direction is not a negative current of electricity flowing in a negative direction. These two currents involve the motion of masses of matter in opposite directions. Do these currents co-exist in the conducting wire? Is a direct-current dynamo pouring oppositely moving electrons into the opposite ends of the conductor? After a few thousand years of continuous use, may it become clogged and lose in part its conductive properties, acquiring perhaps meanwhile radioactive properties?

Wheatstone made a famous experiment on the discharge of a Leyden jar, which was thought very instructive in his day. But did his contemporaries really learn the lesson which that experiment teaches. The sparks at the two gaps nearest the terminals of the conductor were formed before the central spark appeared. Have we not here evidence that the positive and negative currents, moving in opposite directions, begin at the opposite terminals, and only become superposed after an appreciable time interval?

In a Geissler tube having a length of about 
fifty feet, J. J. Thomson found the positive luminescence to travel in a direction opposite that of the cathode particles in the Crookes tube, with a velocity somewhat greater than half the velocity of light. If this involved an actual transfer of electrons by some hand to hand process; it did not involve matter which was concerned in producing spectrum lines, since no Doppler effect is shown in the positive luminescence (Spottiswoode and Moulton). It might be suggested that the positive luminescence was here produced by cathode rays which found their way around the bends of this long tube and finally struck the anode, but this seems very improbable, especially in view of the Wheatstone, experiment.

It seems probable that the discharge from a Leyden jar, or from a Holtz machine, differs from that of a spark coil or from the current originating in an armature of a dynamo. If both positive and negative currents exist in these last-named circuits, they are superposed in their origin, where the E.M.F. is produced. In the Holtz machine, as in the Leyden jar discharge, the positive and negative charges are separately accumulated, and in this case the positive and negative currents may perhaps be prevented from being superposed in the same discharge conductor. One terminal of the machine or jar may be connected to a large many-pointed conductor, suspended in the outer air on silk fibers. That terminal of the machine is then grounded on the dust particles in the air. The other terminal may be grounded either in a like manner, or on the gas pipe. Wheatstone gaps may be made in either of these circuits of unipolar discharge. These gaps may be either in open air or in tubes having any degree of exhaustion. Wheatstone's experiment under these conditions is likely to tell us something about the motion of positive and negative electricity in a conductor.

It is interesting to observe here that a Crookes tube will operate well in either of these unipolar circuits. The same exposure to the $\mathrm{X}$-ray will give pictures of equal density when developed together in the same bath. In one case, however, the cathode terminal is connected to the negative terminal of the machine. In the other circuit, it is connected to the air contact, and is acted upon only inductively by the anti-cathode which is connected to the positive terminal of the machine. In the first case the cathode discharge appears normal and stable. In the second case, it seems unsteady, it is greatly affected by the motion of surrounding bodies, and it can be suppressed entirely by bringing the open hands near the tube so as to partly enclose it.

The pointed air terminal may be replaced by a flaming gas torch made of gas-piping closed at its upper end and having many small perforations, the lower end being connected with the gas main by rubber and glass tubing, the latter being kept dry by heating. The carbon particles then serve as the carriers. An insulated water tank in open air, from which the water escapes in a fine spray, is also effective.

If what we call the free charges on the terminals of the machine are delivered to the small particles which float off into the air, it would seem that in these unipolar discharges we may find that even if positive and negative currents are superposed they may not be equal in value. For certainly in both circuits the dominating action comes from the machine.

Francts E. Nipher.

\section{SCIENTIFIC NOTES AND NEWS.}

Professor Simon Newcomb has been elected a corresponding member of the Vienna Academy of Sciences.

IT is reported that the Nobel prize for medicine will this year be awarded to Dr. Robert Koch.

Professor William T. Sedgwick, head of the biological department of the Massachusetts Institute of Technology, has been elected an honorary member of the New England Water Works Association.

Professor Martens, director of the Institute for Testing Materials at Berlin, has been elected a member of the Berlin Academy of Sciences.

Professors Paul Mansion, professor of mathematics, at the University of Genth, M. 